\title{
QUANTIFYING BENEFITS OF KNOWLEDGE MANAGEMENT SYSTEM -A CASE STUDY OF AN ENGINEERING CONSULTING FIRM
}

\author{
Wen-der $\mathrm{Yu}$ \\ Professor \\ Institute of Construction Management \\ Chung Hua University \\ Hsinchu, Taiwan \\ E-mail: wenderyu@chu.edu.tw
}

\author{
Pei-lun Chang \\ Graduate Research Assistant \\ Institute of Construction Management \\ Chung Hua University \\ Hsinchu, Taiwan \\ E-mail: lunlun@ms38.url.com.tw
}

\author{
Shen-jung Liu \\ Manager \\ Department of Business and Research \\ China Engineering Consultants Inc. \\ Teipei, Taiwan \\ E-mail: sjliu@ceci.org.tw
}

\begin{abstract}
Quantifying the benefits of a knowledge management system (KMS) is a difficult job. Very little literature was found to report the rate of investment (ROI) resulted from a KMS. Quantification of returns from KMS investments involves several tasks: identification of value added knowledge management (KM) activities, identification of benefits generated by the value added KM activities, and quantifying the values of benefits. This paper is dedicated to the development of quantitative models for measuring time, man-hour, and cost benefits resulted from a KMS of an engineering consulting firm. Details of the proposed quantitative KMS benefit models are presented with a case study application to a local leading engineering consulting firm. It is found from the case study that the average time benefit (TB) is $63 \%$; the average man-hour benefit (MHB) is $73.8 \%$; and the average cost benefit is $86.6 \%$.
\end{abstract}

Keywords: Knowledge management, Quantification, Benefits, Engineering consultant

\section{INTRODUCTION}

In the past decade knowledge management (KM) has been getting more and more attention, while the assessment of its returns is lagging behind. In other words, organizations spend a lot of resources in improving their knowledge infrastructure, both for hardware and software, while less effort is invested to measure the results of their knowledge management endeavors. Very little literature is found on measuring the value of KMS due to a key problem: lack of quantification methods for benefits resulted from KMS. Without such quantitative models, top management of the organization could not determine the benefits generated from KMS, so that decision is hard to make on how much founding should be invested and what strategies can be adopted to improve the performance of KMS.

This paper presents the development of quantitative models for benefits of a KMS. Three types of benefits are modeled: (1) time benefit - saving of time in solving a problem due to the contribution of KMS; (2) man-hour benefit-saving of man-hours in solving a problem due to the contribution of KMS; (3) cost benefit - saving of cost in solving a problem due to the contribution of KMS. The model development process consists of: (1) identification the types of benefits obtained from KMS; (2) identification of value adding activities in the problem solving process, which related to usage of a KMS; (3) formulation of quantitative models. A case study is conducted to verify the applicability of proposed quantitative models. The case KMS is selected from a local leading consulting firm named CECI whose headquarters located at Taipei.

This paper is prepared in the following manner: previous works on measuring values of a KMS are reviewed in Section 2; then identification of benefits and value-adding activities with KMS is described in Section 3; the quantitative model for each type of benefit generated from a
KMS is developed and presented in Section 4; in Section 5, a case study application of the proposed models to a KMS is demonstrated; finally, conclusions are drawn and future works are recommended in Section 6.

\section{RELATED WORKS ON QUANTIFYING KMS BENEFITS}

This section reviews previous works on the quantification of KMS performance. The focuses are on the intellectual assets to measure, the measurement approaches, and the measuring systems.

\subsection{Quantification of intellectual assets}

As the value generated by a KMS is an intellectual asset, methods for measuring intellectual assets can be adopted to measure the value of a KMS, too. Chang and Wang [1] categorized methods for valuation of intellectual assets into three classes: (1) first generation indexes-including Navigator, BSC, and Intangible Asset Monitor; (2) second generation indexes-including Intellectual Capital Index (IC Index), Intellectual Capital Audit (IC Audit); (3) financial measures - including market-to-book ratio method, Tobin's q method, and Economic Value Added (EVA) method.

For the first generation indexes, the Navigator classifies intellectual capitals into various types and measures the intellectual capitals with proxy variables that are multiplied with pre-defined weightings. The BSC views the intellectual capital from four perspectives: (1) learning and growth; (2) internal processes; (3) customer; (4) financial. Key performance factors (KPIs) are defined in each perspective. The intellectual capital is then measured with values of KPIs through an aggregation process. The Intangible Asset Monitor (IAM) differentiates intellectual capitals into various types and determines measuring 
dimensions such as growth, efficiency, etc. Finally, an intellectual capital report is generated for the management purpose.

Both the IC Index and IC Audit approaches in the second generation try to relate the intellectual indexes with financial ratios and convert into a single indexing system. In the financial measuring methods, the Market-to-book ratio measures the intellectual assets by subtracting the tangible asset value from the market value. This method is highly influenced by the stock price in the market. The Tobin's q method is based on the theory proposed by the Nobel Economic Prize winner James Tobin from Yale University. The Tobin's q is defined as the market value of a firm's assets (a firm's productive resources) divided by replacement value (current cost of replacing the firm's assets) of the firm's assets. The EVA is a method of Performance evaluation that adjusts accounting performance for investors' required return on investment. Suppose a division produces a $12 \%$ return on Capital invested. Given the Risk of the division's business line would have. If investors would usually require $14 \%$ on capital invested, the division destroyed Shareholder value by the EVA metric. The EVA measure intellectual capital by the equation: "EVA=Net earning after tax-(weighted average capital cost (total asset - liquid asset))".

All of the above methods valuate the intellectual assets from viewpoint of the organization (or corporate) level. They can be conceived as the macro measures for benefits of a KMS. However, the overall indexes may not reflect the actual benefits generated solely by KMS. For instance, a strategic decision of top manager may cause overrun of a project, which is not due to KMS. A better approach is to develop a specific quantification method for KMS that is not affected by factors other than knowledge management activities

\subsection{Measurement approaches of KMS results}

Swaak et al. [2] conducted as survey and concluded that there are two major measurement approaches related to knowledge management results: (1) questionnaire approach; (2) multiple indicators approach. Within the 'questionnaire approach', a questionnaire with closed and open questions, completed by participants of a KMS reveals the profile of an organization. Usually, the profile is used in subsequent interviews and workshops. Within this approach, major concepts are 'extent of knowledge sharing' and 'learning potential' of an organization. The 'multiple indicator approach' roughly makes a distinction between 'customer capital', 'innovation capital', 'financial capital', 'internal business processes', and 'human capital'. For each category, a large number of indicators-- mostly objective and quantitative-- is collected.

\subsection{Performance measurement of KMS}

There are very few research reports found from literature on performance evaluation of a KMS. The most related work discovered in literature was a work done by del-Rey-Chamorro et al. in Cambridge University [3]. They developed an eight-step framework to create performance indicators for knowledge management solutions. The framework consists of three stages: (1) strategic level-comprising of measures that evaluate the organization's goals; (2) intermediate level-comprising indicators that link the process performance indices at the operational level to the business performance indicators in the strategic level; and (3) operational level-comprising indicators that represent the measurable process performance of a KMS. del-Rey-Chamorro et al.'s work can be very useful for creating performance indicators of a KMS, however, their work was primarily developed based on the observations of KMS in manufacturing industry.

A recent work reported by Mezher et al. on a KMS in a mechanical and industrial engineering consulting firm [4] in middle-east is closely related to this paper. Their paper details the step-by-step implementation of KMS in the case company and lessons learned on the benefits of KMS implementation. Unfortunately, their work didn't describe the evaluation of the performance of KMS. However, at the end of the paper, the authors addressed: "(Future researchers) should set up some quantitative measures to show the financial benefits of the KMS". It pointed out the importance of quantitative performance evaluation for a KMS.

Even though previous work on quantitative performance evaluation of KMS is rare, the similar study in performance management (PM) area is quite plenty even in construction industry. Bassion et al. addressed that in developing a conceptual framework for measuring business performance in construction should take into account the organization's business objectives [5]. They also conducted empirical experiments on two case construction firms in UK. A systematic analysis model based on IDEF0 was also developed for the proposed framework.

Bassion et al.'s work was theoretically based on some existing performance measurement systems such as Balanced Scorecard (BSC) [6], European Foundation for Quality Management (EFQM) excellence model [7], and Key Performance Indicators (KPI) [8]. The above systems provide useful indicators that can be adopted for performance evaluation in the present research.

\section{IDENTIFICATION OF BENEFITS GENERATED BY KM ACTIVITIES}

Before quantifying benefits of a KMS, the types of benefits to be quantified and the knowledge management (KM) activities that really add values to the problem solving process should be identified. After determining the types of benefits to quantify, the critical value adding KM activities is analyzed and surveyed to formulate the quantitative benefit model.

\subsection{Types of benefits generated by a KMS}

The benefits resulted from a KMS can be categorized into two types: (1) tangible benefits - the utilization of KMS can expedite problem solving process and result in several tangible benefits for the organization, such as time 
shortening, cost reduction, and man-hour saving; (2) intangible benefit - the intangible assets of the organization may be increased due to the use of KMS, such as the reputation of the firm, knowledge repository of the firm, growth of experience and knowledge of the staffs, and cultural of knowledge sharing of the firm. Several workshops with the KMS top management of CECI were conducted to determine the type of benefits to be quantified. The workshops concludes that only the tangible benefits including time, cost, and man-hour benefits will be quantify in this research.

\subsection{Identification of value-adding activities}

Adoption of KMS will result in re-engineering of the internal business and operation processes of the organization. In order to identify the value adding KM activities, the traditional problem solving process is compared with that of KMS to find out the critical steps where benefits are generated. Figure 1 shows the problem solving process in traditional organization. In Figure 1, the problem is raised by the initiator to a sponsor (can be the department or section head) first, then the sponsor determines a list of the relevant departments and notifies them to provide problem solving support. The notified departments then selected proper members to join the problem solving task force. After then, a cyclic problem solving process starts with periodical or non-periodical meetings until the problem is solved.

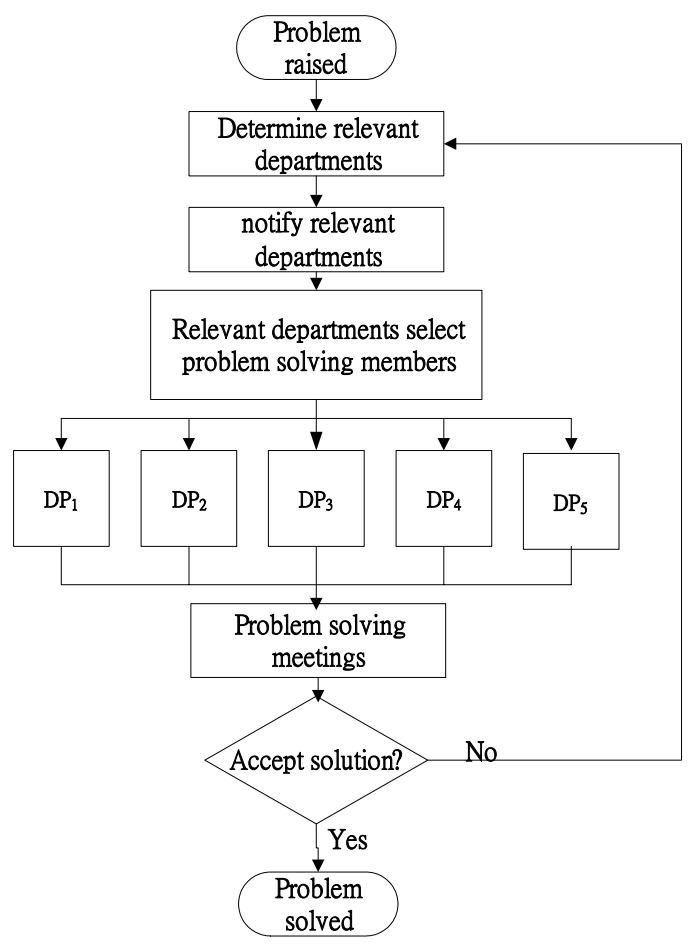

Figure 1 Traditional problem solving process

The same problem is considered for the solving with a KMS. Figure 2 shows the KMS process in solving the same problem. In Figure 2, the problem is raised by any staff of the organization sometime somewhere. The raised problem is then posted in the related community of practices (COPs). Participants of the COPs respond their answers and solutions, or just ideas to the problem in the COPs. Since the communications between problem raiser and participants are transparent to all participants, no explanation to the participants is needed. Moreover, as the participants are from all contexts (some time external experts are involved), efficient knowledge conversions is expedited. This is so called the "The Medici Effect" [9]. When the satisfactory solution is obtained by the problem raiser, detailed solution is developed and problem is solved.

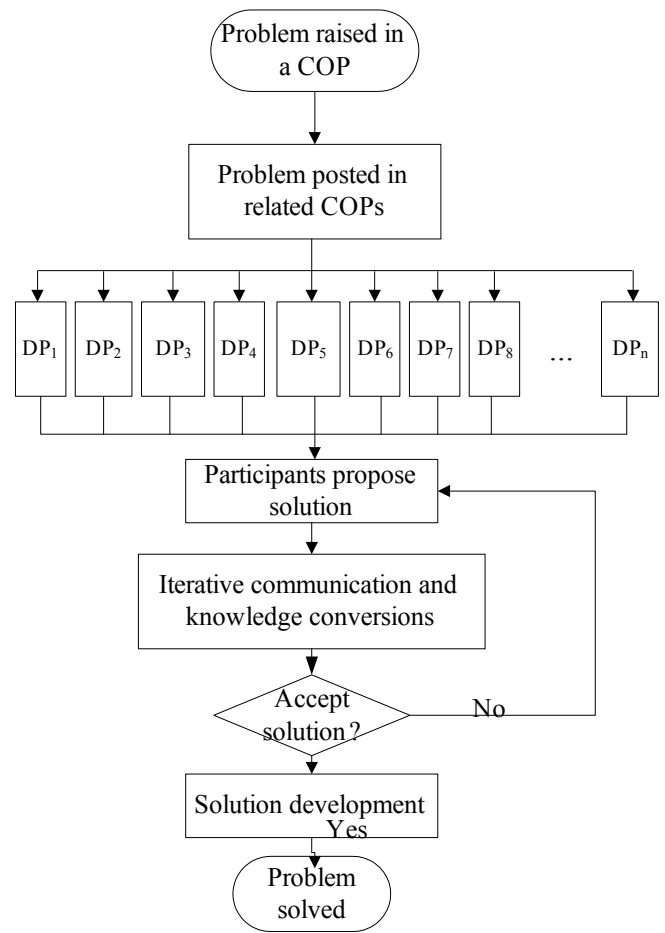

Figure 2 KMS problem solving process

By comparing the problem solving process of traditional and KMS approaches, it is found that KMS provides a better communication platform for KMS participants so that The Medici Effect can happen. Moreover, KMS also provides knowledge based system that expedites the "combination" conversion in Nonaka's knowledge creation spiral [10]. The quantitative benefit model is then formulated to measure the time, man-hour, and cost of both traditional and KMS problem solving processes. The model development is described in details in the next section.

\section{QUANTITATIVE BENEFIT MODELS}

In this section, the quantitative model for benefit of KMS is described in details. The quantitative model consists of three types of benefits for a KMS: (1) time-benefit — saving of time required to solve a problem with KMS compared with the time required in the traditional process; (2) man-hour benefit - saving of man-hours required to solve a problem with KMS compared with the man-hours required in the traditional process; (3) cost benefit-saving of cost 
spent to solve a problem with KMS compared with the cost spent in the traditional process.

\subsection{Time benefit}

The time benefit measures the saving of problem solving time with the aid of KMS compared with traditional problem solving approach. In this paper, the time benefit is measured in the following with Equation (1):

$$
T B(\%)=\frac{N D_{T}-N D_{S}}{N D_{T}} \times 100 \%
$$

Where, $N D_{T}$ is the working days required for traditional problem solving approach, it is estimated by the problem raiser based on previous experience; $N D_{S}$ is working days required for problem solving with KMS, it is calculated with data recorded in KMS system and questionnaire survey with the problem raiser; $T B$ is the ratio of time saving (time benefit) measured in percentage $(\%)$

\subsection{Man-hour benefit}

Man-hour benefit measures the saving of efforts needed to solve a problem with KMS compared with the traditional approach. In order to calculate man-hour benefit, both man-hours spent in traditional approach and KMS approach need to be recovered. Traditionally, the problem is solved via meetings. Usually, only staffs of the relevant department are gathered in meetings. The problem solving process in KMS is quite different. In KMS, the problem is posted in a COP and all members of the COP participate in discussion of the problem solution. Such arrangement allows engineers with different contexts intersect one another in a COP so as to make Johansson's "the Medici effect" happen.

The required man-hours for solving a problem in traditional approach is estimated with Equation (2), while the required man-hour for solving a problem in a KMS is estimated by Equation (3).

$$
T T T=N D_{T} \times\left(M P_{T} \times O T \times \Delta \%\right)+\left(M N_{T} \times M T_{T} \times M P_{T}\right)
$$

Where, $N D_{T}$ was defined in Equation (1); $M P_{T}$ is the number of participants in traditional problem solving meetings; $O T$ is the average daily working hours of the meeting participants (hr); $\Delta \%$ is the average percentage of daily working hours spent by the meeting participants in solving the problem, it is obtained by questionnaire survey with the participants; $M N_{T}$ is total number of meetings required to solve the problem; $M T_{T}$ is average time (hr) per meeting; and TTT is total man-hours required to solve the same problem in traditional approach (hr).

$$
S T T=\sum O R T_{S}+H R T_{S}+F A T_{S}
$$

Where, $O R T_{S}$ is the time spent by the replier during the working hours; $H R T_{S}$ is the time spent by the replier after the working hours; $F A T_{S}$ is the additional time required to develop the finally solution for the problem after the most satisfactory response is obtained (hr); STT is the total man-hours spent for problem solving in KMS.

The ratio of man-hour saving is calculated in the following equation:

$$
M H B \%=\frac{T T T-S T T}{T T T} \times 100 \%
$$

Where, TTT and STT were defined in Equation (2) and

$$
\text { (3); } M H B \text { is man-hour benefit in percentage (\%)。 }
$$

\subsection{Cost benefit}

Cost benefit is always a central concern of top management of a firm as the cost relates directly to the financial performance. One of the primary objectives of KMS investment is cost saving. The cost benefit measures difference of costs between the traditional approach and KMS approach in solving the same problem. The cost spent for problem solving with traditional approach is estimated by Equation (5), while the cost spent for problem solving with KMS approach is estimated by Equation (6).

$$
\begin{aligned}
& T T C=\left[N D_{T} \times\left(M P_{T} \times O T \times \Delta \%\right)\right. \\
& \left.+\left(M N_{T} \times M T_{T} \times M P_{T}\right)\right] \times E A P
\end{aligned}
$$

Where, $N D_{T}, M P, O T, \triangle \%, M N_{T}$, and $M T_{T}$ were defined in Equation (2); EAP is the average hourly salary of the participants $(\$ / \mathrm{hr})$; and TTC is the total cost of problem solving in traditional approach.

$S T C=\left[\sum O R T_{S}+F A T_{S}\right] \times E A P$

Where, $O R T_{S}$ and $F A T_{S}$ were defined in Equation (3); $E A P$ was defined in Equation (5); and $S T C$ is the total cost of problem solving in KMS approach.

Finally, the ratio of cost saving is calculated in the following with Equation (7):

$$
C B \%=\frac{T T C-S T C}{T T T} \times 100 \%
$$

Where, TTC and STC were defined in Equation (5) and (6) respectively; $C B$ is cost benefit in percentage (\%).

\section{APPLICATION CASE STUDY}

In order to verify the applicability of the proposed KMS quantitative benefit model, a local leading A/E consulting firm, China Engineering Consultants, Inc. (CECI), is selected for case study.

\subsection{Background of case organization}

The CECI is one of leading A/E firms in Taiwan. It was established in 1969 primarily for the purpose of promoting Taiwan's technology and assisting in the economic development of Taiwan and other developing countries. The number of full-time staffs of the firm is about 1,700. Among those around 800 are in-house staffs in headquarter located in Taipei, the other 900 are allocated in branches 
and site offices around the island. Headquarter, braches, and site offices are connected by Intranet.

The structure of the case A/E firm consists of five business groups: (1) Civil Engineering Group; (2) Railway Engineering Group; (3) Electrical and Mechanical Engineering Group; (4) Construction Management Group; and (5) Business and Administration Group. Each business group includes several functional departments. The annual revenue of case A/E firm is around 4 billion TWD (128 million USD). According to the information disclosed by the firm, more than $1,700 \mathrm{~A} / \mathrm{E}$ projects were finished in the past thirty years. Totally volume (construction budget) of the finished projects exceeds 300 billion USD.

\subsection{The case KMS}

The implementation of KMS in CECI started four years ago. Unlike most of other examples of KMS implementation, CECI chose to develop the KMS completely by their own staffs without help of external consultants. At the beginning, the KMS was proposed by the Department of Business and Research. Soon, it was realized that engineers of Department of IT should be included in order to resolve the technique problems encountered in implementation of prototype system. The commercial software, Microsoft SharePoint ${ }^{\circledR}$ was adopted to develop the KMS. The system development took one year to complete the prototype.

The prototype KMS began to operate after one year of the project commencement. It was found quickly that development of software KMS is not a tough job compared with the building of the culture and atmosphere for successful operation of the KMS. More that 40 communities of practice (COP) were established. The number of COP is varying based on an enter-and-exit regulation. That is, continuous evaluation of COP is performed to determine whether it should be maintained or closed down. The manager of COP is in charge of all activities for promotion of the knowledge creation in that COP. Incentives were provided by the company to stimulate the establishment of knowledge sharing atmosphere. To date, the KMS has been operating for three years. The KMS has been modified quite a bit from its prototype three years ago. One of the most significant modifications was the introduction of SOS system for emergent problem solving. The case KMS of CECI comprises of eight centers: (1) Administration Centre; (2) Business Centre; (3) Computer Resource Centre; (4) Management Information Centre; (5) Project Centre; (6) Knowledge Centre; (7) Activity Centre; and (8) Consulting Centre.

\subsection{Selected SOS subsystem}

The SOS system is a special COP in the KMS of CECI, which provides a tentative forum for emergent problem encountered by engineers/managers. Once the problem is posed as SOS-problem, it is posted on SOS board on the first page of the KMS for emergent discussions. Such arrangement forces every participant of KMS to take a look at the posed problem. So that it generally receives attentions and usually has a better chance to be solved by responders. Problems posted on SOS board receive no response within one working day will be automatically removed and transferred to relevant $\mathrm{COP} / \mathrm{COPs}$. After then, it becomes regular topic for discuss in COP.

\subsection{Parameters survey}

In order to test the proposed PISP model, historical SOS cases were randomly retrieved. Totally fifty-two SOS cases were sampled from 596 historical cases, in which 8 cases were posed by staffs from Civil Engineering Group, 19 cases were posed by staffs from Railway Engineering Group, 2 cases were posed by staffs from Electrical and Mechanical Engineering Group, 18 cases were posed by staffs from Construction Management Group, and 5 cases were posed by staffs from Business and Administration Group. Questionnaires were prepared for surveying with the problem raisers of the fifty-two SOS cases to acquire information on: (1) time spent on preparing descriptions and clarifications of the problem; (2) satisfaction level of each response evaluated by the problem raiser; (3) time spent by the problem raiser to develop the final solution after the most satisfactory response was obtained; and (4) estimated number of meetings, staffs involved, and average time to prepare for the meetings required to solve the same problem in the traditional approach. Questionnaires were also prepared to survey with the repliers for information on: (1) the time spent to prepare the responding article; (2) the mode (socialization, externalization, combination, and internalization) of knowledge conversion he/she has experienced in preparing the responding article. Other information was acquired automatically from KMS including: (1) the department that the problem raiser and response replier belong to; (2) the date and time when the problem was posted or the response was replied; (3) the location (office/home) where the article is replied.

817 questionnaires were sent to 419 KMS participants including the President, Vice Presidents, Associate Managers, Sector Directors, and engineers. Totally, 418 responses were received, among which 309 were effective. Percentage of effective responses was $40 \%$. However, only 17 out of the 52 SOS cases were responded. Therefore, the 17 responded SOS cases will be further analyzed in the following subsections to measure their quantitative benefits.

Table 1 Questionnaire survey statistics

\begin{tabular}{|l|l|l|l|l|}
\hline $\begin{array}{l}\text { Questionnair } \\
\text { e }\end{array}$ & submitted & response & valid & $\%$ valid \\
\hline Quantity & 817 & 418 & 309 & $40.0 \%$ \\
\hline
\end{tabular}

5.4 Quantitative benefits calculation

Equation $(1) \sim(7)$ defined in Section 4 are applied to quantify the time, man-hour, and cost benefits of the 17 SOS cases based on parameters obtained in the previous subsection. The results of the benefit quantification are shown in Table 2. It is noted in Table 2 that the average time benefit (TB) is $63 \%$; the average man-hour benefit 
(MHB) is $73.8 \%$; and the average cost benefit is $86.6 \%$. That means that the KMS approach can save $86.6 \%$ traditional problem solving cost in the 17 SOS cases.

Table 2 Results of benefit calculation of the 17 SOS cases

\begin{tabular}{|c|r|r|r|}
\hline Case & $\begin{array}{r}\text { Time benefit } \\
T B(\%)\end{array}$ & $\begin{array}{c}\text { Man hr. benefit } \\
M H B(\%)\end{array}$ & $\begin{array}{c}\text { Cost benefit } \\
C B(\%)\end{array}$ \\
\hline 1 & $70.0 \%$ & $92.0 \%$ & $75.0 \%$ \\
\hline 2 & $66.7 \%$ & $71.7 \%$ & $28.2 \%$ \\
\hline 3 & $71.4 \%$ & $88.8 \%$ & $87.2 \%$ \\
\hline 4 & $60.0 \%$ & $89.5 \%$ & $80.8 \%$ \\
\hline 5 & $80.0 \%$ & $70.2 \%$ & $60.7 \%$ \\
\hline 6 & $0.0 \%$ & $93.6 \%$ & $80.0 \%$ \\
\hline 7 & $93.3 \%$ & $96.2 \%$ & $94.2 \%$ \\
\hline 8 & $85.7 \%$ & $87.6 \%$ & $78.7 \%$ \\
\hline 9 & $66.7 \%$ & $71.5 \%$ & $26.8 \%$ \\
\hline 10 & $80.0 \%$ & $97.0 \%$ & $85.0 \%$ \\
\hline 11 & $0.0 \%$ & $87.0 \%$ & $70.8 \%$ \\
\hline 12 & $71.4 \%$ & $98.1 \%$ & $78.8 \%$ \\
\hline 13 & $50.0 \%$ & $93.1 \%$ & $88.8 \%$ \\
\hline 14 & $66.7 \%$ & $89.1 \%$ & $85.1 \%$ \\
\hline 15 & $66.7 \%$ & $80.7 \%$ & $68.8 \%$ \\
\hline 16 & $71.4 \%$ & $96.9 \%$ & $94.2 \%$ \\
\hline 17 & $71.4 \%$ & $71.2 \%$ & $71.2 \%$ \\
\hline Average & $63.0 \%$ & $86.6 \%$ & $73.8 \%$ \\
\hline
\end{tabular}

\section{CONCLUSIONS AND FUTURE WORKS}

\subsection{Conclusions}

This paper presents the development of quantitative models for benefits resulted from a KMS. Only tangible benefits such as time shortening, man-hour saving, and cost reduction are considered in the quantitative models. A case study is conducted in a local leading engineering consulting firm to verify the applicability of the proposed quantitative benefit models. The SOS (emergent problem solving) subsystem of the case KMS is selected for in-depth case study. 52 cases were randomly sampled from 596 historical SOS cases. Questionnaire surveys were conducted with 419 participants of the selected SOS cases. $40 \%$ effective responses for $17 \mathrm{SOS}$ cases were received. It is found from case study that averagely $63 \%$ for time benefit (TB), $73.8 \%$ for man-hour benefit (MHB), and $86.6 \%$ for cost benefit were achieved in the 17 SOS cases.

\subsection{Future works}

Due to time constraint, only the benefits resulted from problem solving process are quantified. Benefits resulted from other KM activities such as bid preparation is not included in this research, which can be an interesting topic for future research. Moreover, intangible benefits such as the intellectual assets accumulated by KMS can be considered in the future works, too.
The founding of this research project was partially supported by the National Science Council, Taiwan, under project No. NSC 95-2221-E-216-049. Sincere appreciations are given to the sponsor by the authors.

The valuable case study information presented in this paper was provided by CECI, Taipei. The authors would like to express sincere appreciations to Dr. Wu, J. H., Manager, Mr. Chen, G. L., and other staffs of the Department of Business and Research and Department of Information Systems, China Engineering Consultants, Inc., Taipei, Taiwan.

\section{REFERENCES}

[1] C. Y. Chang and M. T. Wang, "Introduction to the Valuation of Construction Intellectual Capitals," (64), 50-59, 2005. (in Chinese)

[2] J. Swaak, A. Lansink, E. Heeren, B. Hendriks, P. Kalff, J-W. Den Oudsten, R. Böhmer, R. Bakker, and C. Verwijs, "Measuring knowledge management investments and results: two business cases," paper presented at the $59^{\text {th }}$ AEPF-Tagung, Bremen, Oct. $3^{\text {rd }}$, 2000, Germany, 2000.

[3] F. M. del-Rey-Chamorro, R. Roy, B. van Wegen, and A. Steele, "A framework to create key performance indicators for knowledge management solutions," Journal of Knowledge Management, 7(2) 46-62, 2003.

[4] M. Mezher, M. A. Abdul-Malak, I. Ghosn, and M. Ajam, "Knowledge Management in Mechanical and Industrial Engineering Consulting: A Case Study," Journal Management in Engineering, ASCE, 21(3), 138-147, 2005.

[5] H. A. Bassion, A. D. F. Price, and T. M. Hassan, "Building a conceptual framework for measuring business performance in construction: an empirical evaluation," Construction Management and Economics, 23(5), 495-507, 2005.

[6] R.S.Kaplan and D.P. Norton, "The balanced scorecard - measures that drive performance," Harvard Business Review, January-February, 71-79, 1992.

[7] British Quality Foundation, "The Model in Practice-Using the EFQM Excellence Model to Deliver Continuous Improvement," The British Quality Foundation, London, UK, 2002.

[8] S. Beatham, C.J. Anumba, T. Thorpe, and I. Hedges, "KPIs - a critical appraisal of their use in construction," Benchmarking: An International Journal, 11(1), 93-117, 2004.

[9] F. Johansson, "The Medici Effect: Breakthrough Insights at the Intersection of Ideas, Concepts, and Cultures," Harvard Business School Press, Cambridge, MA, USA, 2002.

[10] I. Nonaka, "A dynamic theory of organizational knowledge creation," Organization Science, 5(1), 14-37, 1994.

\section{ACKNOWLEDGEMENT}

